\title{
SMALL THINGS HAVE A BIG IMPACT: NEW TRENDS IN IMPLANT DENTISTRY
}

\author{
Angel Mary Joseph, Suja Joseph, Nicholas Mathew, Ashwin Thomas Koshy \\ Department of Prosthodontics and crown and bridges, Pushpagiri College of Dental Sciences, Kerala, India
}

\section{ARTICLE INFORMATION:}

Article History:

Received: 01 October, 2017 Accepted in

revised form: 03 June, 2018

Published:28 December 2018

Corresponding author:

Angel Mary Joseph

E-mail: angelmaryjoseph@gmail.com

\section{Keyword:}

Nanodentistry, nanotechnology, implant surface modifications, nanosensors, nanotubes.

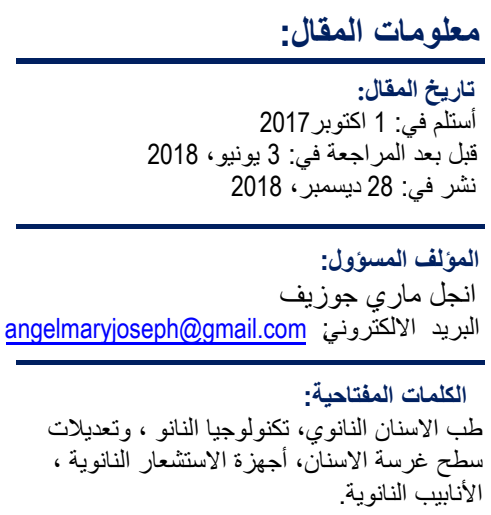

\begin{abstract}
:
In the twenty first century, nanotechnology has already offered numerous possibilities in implant dentistry. One nano step for man has resulted in a giant leap in implant dentistry. The advent of nanotechnology had created an opportunity for the engineering of new dental implant materials. This technology has also been used to enhance osseointegration by surface modifications of dental implants. Nanometre-controlled surfaces have ultimately directed the nature of peril-implant tissues and improved the clinical success rate of implant therapy. The possibilities introduced by nanotechnology now permit the tailoring of implant chemistry and structure. Nanotechnology in dental implantology has emerged as a frontier research area of interest in this decade. Long thought to be commercially uninhabitable, the once-barren nanotechnology landscape suddenly looks fertile. With the support of some brightest minds in science and engineering, this emerging field of super small is now firmly on the shortlist of technologies poised to produce big things in implant dentistry. In this article, we have made an attempt to review the current trends and future prospects on the impact of nanotechnology in implant dentistry.
\end{abstract}

\section{الملخص العربي}

$$
\begin{aligned}
& \text { الأثياء الصغيرة لها تأثير كبير: اتجاهات جديدة في زراعة الأسنان } \\
& \text { انجل ماري جوزيف، سجى جوزيف، نبكو لاس ماتثيو، أشوين توماس كوشي }
\end{aligned}
$$

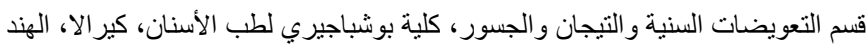

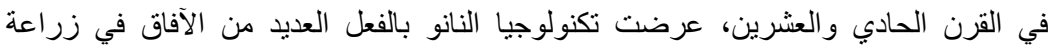

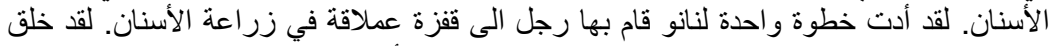

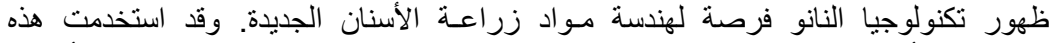

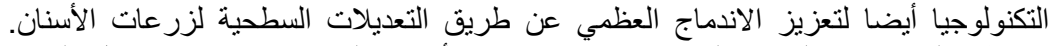

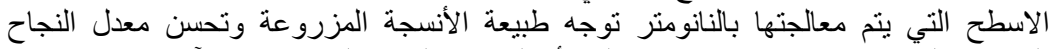

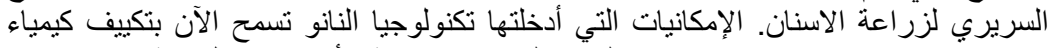

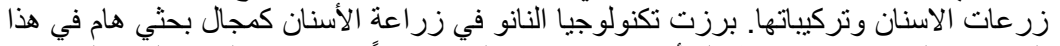

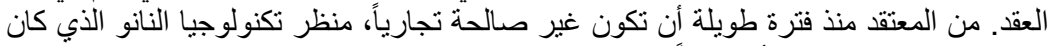

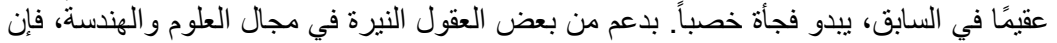

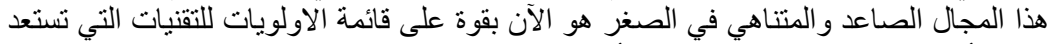

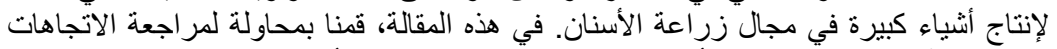

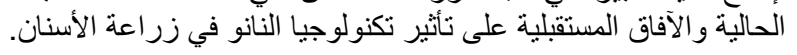

Copyright $\odot$ 2018. LDJ. This is an open access article distributed under the Creative Commons Attribution 3.0 License, which permits unrestricted use, distribution, and reproduction in any medium, provided the original work is properly cited.

Citation:Libyan Dent J 2018, 8: 201812002 -http://dx.doi.org/10.5542/LDJ.v8i0.201812002 


\section{INTRODUCTION}

The Goal of Prosthodontics is to restore the patient to normal contour, function, comfort, aesthetics, speech, and health, regardless of the atrophy, disease, or injury of the stomatognathic system. Assimilation of these features in any prosthesis delivered to the patient is the ideal goal of modern prosthodontic rehabilitation. However, with highly complicated and challenging clinical scenarios which are commonly encountered in the general practice, an ideal replacement of the lost tissues using the conventional techniques may not be always possible. Answer to such a clinical dilemma would probably be Implant therapy.

Oral implantology is one of the fastest growing sciences within dentistry. Ever since its introduction into the field of dentistry by Dr. Branemark, it has undergone numerous modifications and improvements. With each improvement and advancement made, implantology has proved to be a boon in disguise to the society and hence its acceptance by the general population has widely increased despite it being a relatively expensive treatment modality.

The twenty first century has witnessed the application of contemporary engineering techniques and nanotechnologies in the field of implant dentistry. One nano step for man has resulted in a giant leap in implant dentistry. The advent of nanotechnology had created an opportunity for the engineering of new dental implant materials and also enhanced osseointegration by surface modifications of dental implants. Nanometrecontrolled surfaces have ultimately directed the nature of peri-implant tissues and improved the clinical success rate of implant therapy. The possibilities introduced by nanotechnology now permit the tailoring of implant chemistry and structure.

\section{NANOTECHNOLOGY IN IMPLANT DENTISTRY}

As treatment protocols get more advanced and dental implants are placed in more challenging clinical scenarios, a surface that potentially provides a greater rate and extent of osseointegration on a more predictable basis, could be a benefit. The various developments by nanotechnology has addressed these problems to some extent.

Nanotechnology has already proved its merit in implant dentistry by the various surface modifications and altering implant surface nanotopography. Implant surface composition, surface energy, surface roughness and surface topography are the four material related factors which can influence events at bone-implant interface.
Various surface textures have been created by chemical and physical processes ${ }^{1}$ and used to successfully influence cell and tissue responses. Surface textures are of 3 types: Macro, micro and nano. The nanostructured materials exhibit enhanced mechanical, electrical, magnetic and/or optical properties compared to their conventional micron-scale or macro-scale counterparts.

\section{LOOKING FORWARD: THE DENTAL IMPLANTOLOGY OF TOMORROW}

Nanotechnology holds the potential for offering a bright future for dental implantology. It has emerged as a frontier research area of interest in this decade. Long thought to be commercially uninhabitable, the oncebarren nanotechnology landscape suddenly looks fertile. With the support of some brightest minds in science and engineering, this emerging field of super small is now firmly on the shortlist of technologies poised to produce big things in implant dentistry. Some of the potential areas of interest include;

- The revolutionary NanoTite implants: A bone bonding surface.

- Biomimetic coatings on titanium dental implants.

- Incorporation of biologically active drugs into titanium dental implants.

- Nanodiamond encrusted teeth: the future of dental implants.

- Titanium dioxide nanotube surface promises dental implants that heals faster and fight infection.

- Teriparatide slowing alveolar bone loss in jaw.

- Growing dental implants with stem cells.

- Nanosensors integrated into dental implants for detection of acute myocardial infarction.

- Shape memory alloy based implants with titanium nanotube surface.

\section{The Revolutionary NanoTite implants: A Bone Bonding Surface}

The NanoTite ${ }^{\mathrm{TM}}$ Implant starts with the industry-proven OSSEOTITE $®$ Surface at the core. ${ }^{2}$ Next, discrete nanometre scale crystals of calcium phosphate (CaP) are deposited onto the OSSEOTITE Surface substrate by Discrete Crystalline Deposition (DCD). ${ }^{3}$ This renders the NanoTite implants a bone bonding surface 
by interlocking of the newly formed cement line matrix of bone with the implant surface. ${ }^{4}$ The nanoscale topography and potential biologic benefits associated with the CaP crystals may play a key role in enhanced site response, potentially improving clinical predictability and outcomes (Fig 1).

Preclinical studies demonstrate a substantial improvement on the rate and extent of osseointegration for the NanoTite Implant versus the OSSEOTITE Implant. The result is potentially improved bone fixation, which may lead to greater stability for the implant during the critical early healing phases. This may improve predictability in more challenging clinical cases, to include poor bone quality, immediate and/or accelerated loading, short implants, wide diameter implants, simultaneous grafted sites, extraction sockets and aesthetic cases where bone preservation may be critical. ${ }^{5,6}$

This nanoimplant is available from BIOMET $3 \mathrm{i}^{7}$ in two configurations: The NanoTite Certain ${ }^{\circledR}$ Implant is a modified hybrid where the coverage of both the OSSEOTITE Surface and the nano-scale crystals go up to the base of the implant collar and the NanoTite PREVAIL ${ }^{\circledR}$ Implant, which incorporates integrated Platform Switching ${ }^{\text {TM }}$ and has the OSSEOTITE Surface and the nano-scale crystals to the top of the collar, creating a continuous bone-loading surface (Fig 2).

\section{Biomimetic Coatings on Titanium Dental Implants}

Scientists have developed biomimetic implants by coating nanoparticles over dental implants inspired by the natural process of biomineralization. ${ }^{8}$ It has been demonstrated that different cell types respond positively to nanotopography. The aim was to provide metal implants with surface biological properties for the adsorption of proteins, the adhesion and differentiation of cells, and tissue integration. These biological properties are related to the chemical composition, wettability, and roughness of metal implants surfaces. Nanoscale modification of the implant surface could contribute to the mimicry of cellular environments to favour the process of rapid bone deposition. However, it still remains as a challenge for researchers and dental implants manufacturers to control the surface properties at protein and cell levels in the nanometre range.
Recently, three Nano-structured implant coatings have been developed:

Nanostructured processing applied to hydroxyapatite coatings: This is used to achieve the desired mechanical characteristics and enhanced surface reactivity and has been found to increase osteoblast adhesion, proliferation, and mineralization. ${ }^{9}$

Nanostructured diamond: They have ultrahigh hardness, improved toughness over conventional microcrystalline diamond, low friction, and good adhesion to titanium alloys. ${ }^{10}$

Nanostructured metalloceramic coatings: These provide continuous variation from a nanocrystalline metallic bond at the interface to the hard ceramic bond on the surface. ${ }^{10}$

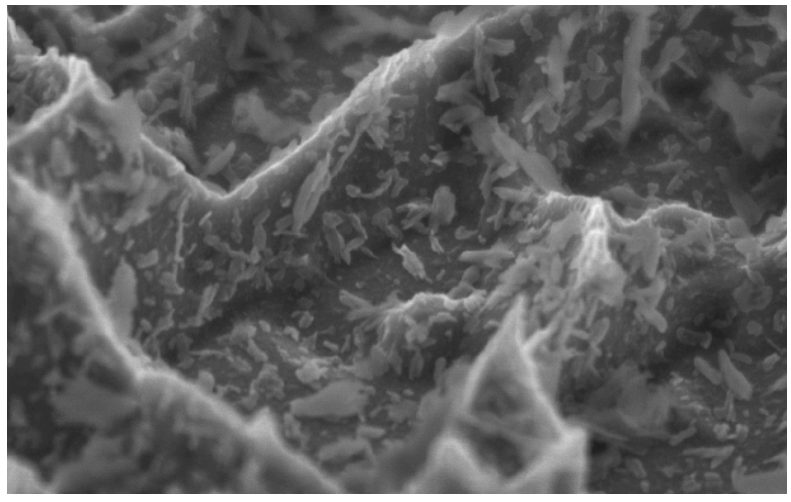

Fig 1. NanoTite implants surface at $2000 \mathrm{X}$ magnification.

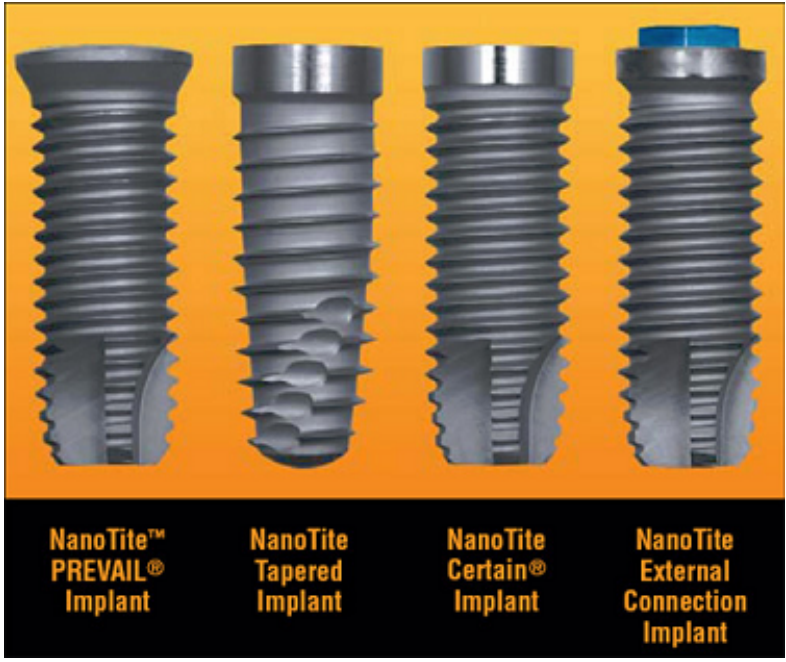

Fig 2. NanoTite implants. 


\section{Incorporation of Biologically Active Drugs into Titanium Dental Implants}

The surface of titanium dental implants may be coated with bone-simulating agents, such as growth factors in order to enhance the bone healing process locally. Members of the transforming growth factor (TGF- $\beta$ ) superfamily, and in particular bone morphogenetic proteins (BMPs), TGF- $\beta 1$, Platelet-derived growth factor (PDGF) and insulin-like growth factors (IGF-1 and 2) are some of the most promising candidates for this purpose. ${ }^{11}$

\section{Nanodiamond Encrusted Teeth: The Future of Dental Implants}

Nanodiamonds, which are created as byproducts of conventional mining and refining operations, are approximately $4-5 \mathrm{~nm}$ in diameter are shaped like tiny soccer balls. Scientists from the UCLA School of Dentistry along with collaborators at NanoCarbon Research Institute in Japan have found a way to use them to improve bone growth and combat osteonecrosis, a potentially debilitating disease in which bone breaks down due to reduced blood flow. ${ }^{12}$

The researchers have discovered that using nanodiamonds to deliver bone morphogenic protein have a potential to be more effective than conventional approaches. The unique surface of the diamonds allows the proteins to be delivered more slowly, which may allow the affected area to be treated for a longer period of time. Furthermore, the nanodiamonds can be administered non-invasively, such as by an injection or on oral tissue. Initial studies indicate that they are well tolerated, which further increases their potential in dental and bone repair applications. This discovery might serve as a foundation for the future of nanotechnology in dentistry by aiding in bony regeneration.

\section{Titanium Dioxide Nanotube Surface Promises Dental Implants that Heals Faster and Fight Infection}

Nanotube surface was developed by Scientist Sukotjo at Michigan Technological University to lower the failure rate of implants. ${ }^{13}$ Titanium dioxide nanotube surface can combat infection, improve healing and prolong the life of dental implants. Studies have showed that bone cells grow more vigorously and adhere better to titanium coated with titanium dioxide nanotube that conventional titanium surfaces. ${ }^{14}$ (Fig 3). Titanium dioxide nanotube surface has been loaded with anti-inflammatory drug sodium naproxen and demonstrated that it could be released gradually after implant surgery. Titanium dioxide nanotube surface can be laced with silver nanoparticles which have anti microbial properties. ${ }^{15}$

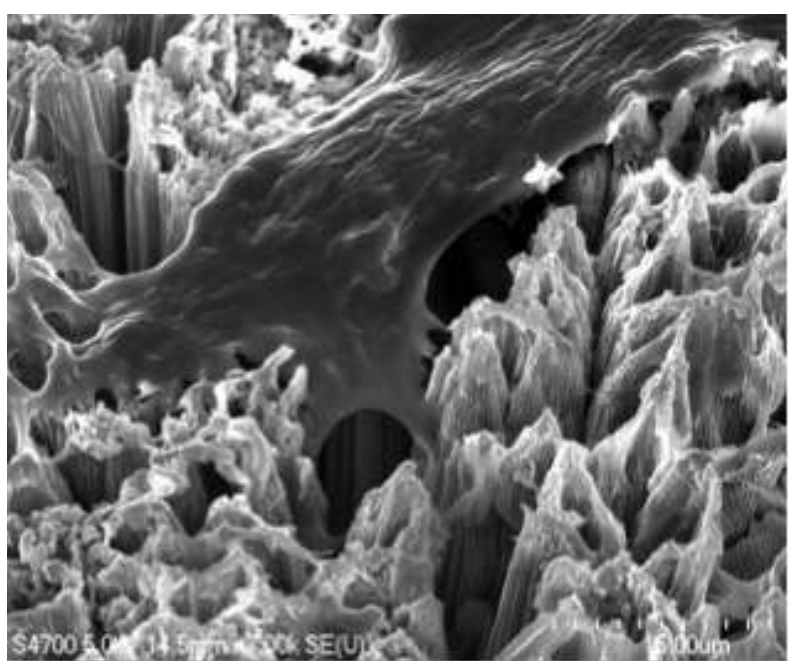

Fig 3. Bone anchoring itself to a surface of titanium dioxide nanotubes.

\section{Teriparatide Slowing Alveolar Bone Loss in Jaw}

A 2010 New England Journal of Medicine article highlighted a novel approach to combat alveolar bone loss seen in patients with severe chronic periodontitis. Teriparatide-a parathyroid hormone (PTH) analogue and a drug most commonly used in treatment of osteoporosis, used daily for six weeks was shown to increase alveolar bone volume, strength and density. ${ }^{16}$ The drug mimics PTH-it stimulates osteoblasts that will elicit osteoclastic differentiation leading to further bone turnover and remodelling with an end result of increased bone mineral density and bone mass. The impact of this discovery in dental implantology is not small. It might be used to enhance osseointegration and reduce failure rates or reduce recovery time or perhaps even make implants available to those who might not be thought of as good candidates for implant therapy.

\section{Growing Dental Implants with Stem Cells}

The concepts of nanotechnology along with tissue engineering could be utilized to grow dental implants using stem cells.Dr.Jeremy Mao and fellow scientists at Columbia University are particularly interested in growing teeth, which might one day make the traditional 
metal-based implants obsolete. Mao designed an experiment using growth factors, a tooth-shaped scaffold and stem cells to see if tooth regeneration was possible. In fact, results were positive and de novo alveolar bone was present with evidence of neovascularisation and mineralization at the scaffold. ${ }^{17}$

\section{Nano Sensors Integrated into Dental Implants for Detection of Acute Myocardial Infarction}

An experimental device was developed by researchers at the National Research Nuclear University, Russia that proves to significantly increase the detection of acute myocardial infarction. ${ }^{18}$ The main novelty is the great mobility of the proposed diagnosis system and its size that significantly improves the process of the modern diagnosis methods in the detection of cardiovascular disease.

The main idea is to build a saliva sensor into a dental implant that is always in the mouth of a patient with the heart attack risk. The particular thing about this saliva sensor is that it is integrated with RFID (Radiofrequency Identification) chip. This chip detects special cardiac biomarkers in saliva using the correspondent chemical reactions. Reaction for each cardiac biomarker undergoes in individual cell in saliva sensor (Fig 4). Saliva sensor gets access to saliva only on demand through small pipes. The whole construction is packed in resin that protects the tag from food and saliva. The RFID chip consists of two main components: RFID tags and RFID readers. The RFID tag looks like a device small enough to fit into a tooth and the RFID reader is implemented as wristband with built in microprocessor. The wristband is used to make the alarm signal in case of a close heart attack. 1 stands for positive reaction on the particular cardiac biomarker and 0 stands for negative reaction.

\section{Shape Memory Alloy Based Implants with Titanium Nanotube Surface}

Nickel-titanium alloys, commonly known as Nitinol are known to exhibit strong shape memory effects. ${ }^{19}$ Shape memory alloy (SMA) based implants made with Nitinol are under intense investigation as a means of providing the implant real time adaptability to the healing process. Currently studies ${ }^{20}$ have been conducted where Titanium nanotube have been formed on the surface of $\mathrm{NiTi}$ implants rendering it biocompatible and also utilizing the shape memory effect of this 'smart material' for orthopaedic implants. This invention has the potential to transform the practice of implant dentistry by achieving dramatic advances in bone mending. However, the primary concern in this context remains regarding the possible cytotoxicity and carcinogenic properties of nickel ions that are potentially released from the implant over an extended period of time..$^{21,22}$

\section{THE DOWNSIDE OF MINIATURIZATION}

The human race has always strived towards newer, progressive technologies. Each new technology brings forth its share of specific advantages and disadvantages. Techniques promising major breakthroughs in implant dentistry utilizing nanotechnology might also have a downside, and hence, must undergo stringent testing before human application. ${ }^{23}$ The strategies thus developed should be amenable to translation into clinical therapies and treatments.

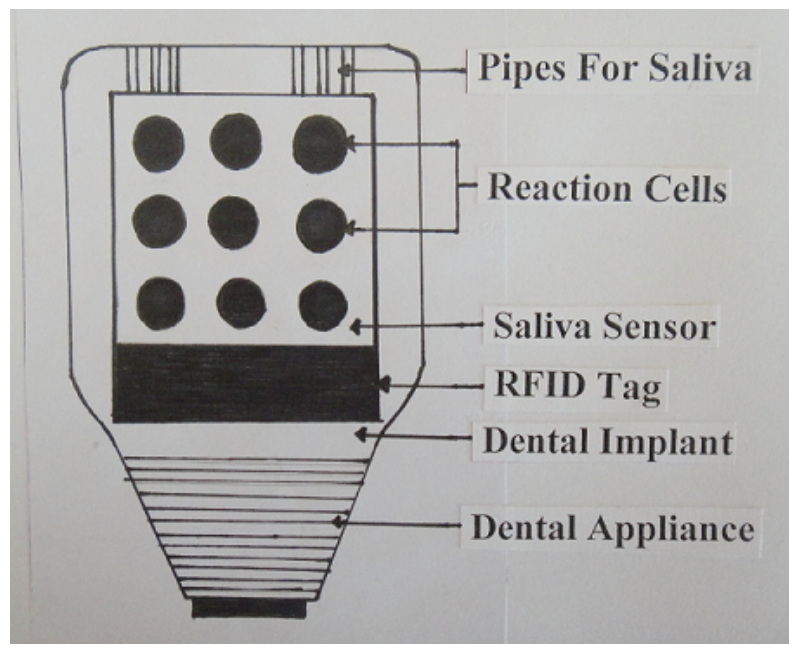

Fig 4. The System Architecture-Nanosensors integrated into dental implants for detection of acute myocardial infarction.

\section{CONCLUSION}

Nanotechnology research is rolling worldwide, having an impact on multiple sectors and with a general belief that dental and biological applications will form the greatest area of expansion over the next decade. This field is mainly driven by an endeavour to bring radical solutions to the area of successful implant dentistry, not fulfilled presently. This technology can drastically improve the osseointegration within the body, the mechanical strength of the implant, and adding 
infection resistance or drug delivery capabilities to the implants. ${ }^{24}$ This miracle technology is in the making of one of the most promising and influential areas of scientific research. These applications will surely pave the way for further research opportunities in device and drug development, thus commencing an era of unprecedented advances in implant dentistry and offer dental implants that last for a lifetime.

\section{REFERENCES}

1. Variola F, Brunski JB, Orsini G, de Oliveira TP, Wazen $R$, Nanci A. Nanoscale surface modifications of medically relevant metals: state-of-the art and perspectives. Nanoscale 2011;3:335-353.

2 http://www.biomet3i.com. One Nano Step For Man, One Giant Leap For Implant Dentistry - BIOMET 3i Introduces Revolutionary Dental Implant. [Assessed 2016 February 10].

3. Mendes VC, Moineddin R, Davies JE. The effect of discrete calcium phosphate nanocrystals on bonebonding to titanium surfaces. Biomaterials 2007;28:4748-4755.

4. Mendes VC, Davies JE. Discrete calcium phosphate nanocrystals render titanium surfaces bone-bonding.Int J Oral Maxillofac Implant. 2007;22:484.

5. Sullivan DY, Sherwood RL, Porter SS. Long-term performance of Osseotite implants: a 6-year clinical follow-up. Compend Contin Educ Dent. 2001;22:326-328.

6. Suttin Z, Gubbi P. Adhesion shear strength of nanometer-scale $\mathrm{CaP}$ crystals applied by discretecrystalline deposition. European Association for Osseointegration. 15th Annual Scientific Meeting. October 5-7, 2006.

7. BIOMET $3 \mathrm{i}$ - Clinical Research Department. NanoTiteTM Implant Pre-Market Evaluation - The Appleseed Project. [assessed 2016 February 10].https://www.google.co.in.

8. Sikirić MD, Gergely C, Elkaim R, Wachtel E, Cuisinier FJ, Füredi-Milhofer $\mathrm{H}$. Biomimetic organic-inorganic nanocomposite coatings for titanium implants. J Biomed Mater Res A. 2009;89:759-771.

9. Mantri SS, Mantri SP.The nano era in dentistry. J Natural Sci Bio Med 2013;4:39-44.

10. Pathan DS, Doshi SB, Muglikar SD. Nanotechnology in implants: The future is small. Univ Res J Dent 2015;5:8-13.

11. Thomas B, Mathew CA, Muthuvignesh J. Nanotechnology applications in prosthodontics: A literature review. J Orofac Res 2014;4:103-110.
12. Moore L, Gatica M, Kim H, Osawa E, Ho D. Multiprotein delivery by Nano diamonds Promotes Bone Formation. J Dent Res. 2013;92:976-981.

13. Shokuhfar T, Sinha-Ray S, Sukotjo C, Yarin AL. Intercalation of anti-inflammatory drug molecules within TiO2 nanotubes. RSC Adv 2013;3:17380-17386.

14. Shokuhfar T, Chang JY, Choi CK, Friedrich C. Biophysical evaluation of osteoblasts on $\mathrm{TiO} 2$ nanotubes,Nanomedicine:Nanotechnology,Biology and Medicine. 2011; Under Revision.

15. Ganguly D, Shahbazian-Yassar R, Shokuhfar T. Recent advances in nanotubes for orthopaedic implants. J Nanotech Smart Mater 2014;1:201.

16. Bashutski JD, Eber RM, Kinney JS, Benavides E, Maitra S, Braun TM, et al. Teraparatide and osseous regeneration in the oral cavity. $\mathrm{N}$ Engl $\mathrm{J}$ Med 2010;363:2396-2405.

17. Kim K, Lee CH, Kim BK, Mao JJ.Anatomically shaped tooth and periodontal regeneration by cell homing. $J$ Dent Res. 2010;89:842-847.

18. Zhukov I, Mikhaylov D, Starikovskiy A. Nano sensors integrated into dental implants for detection of acute myocardial infarction. IJETTCS. 2012;1:85-87.

19. Huang WM, Song CL, Fu YQ, Wang CC, Zhao $Y$, Purnawali $\mathrm{H}$, et al. Shaping tissue with shape memory materials. Adv Drug Deliv Rev. 2013;65:515-535.

20. Hang R, Huang X, Tian L, He Z, Tang B. Preparation, characterization, corrosion behavior and bioactivity of Ni2O3-doped TiO2 nanotubes on NiTi alloy. Electrochim. Acta. 2012;70:382-393.

21. Park YJ, Song YH, An JH, Song HJ, Anusavice KJ. Cytocompatibility of pure metals and experimental binary titanium alloys for implant materials. J Dent. 2013;41:1251-1258.

22. Gu SY, Yan BB, Liu LL, Ren J. Carbon nanotubepolyurethane shape memory nanocomposites with low trigger temperature. Eur Polym J. 2013;49:3867-3877. (2013) 49(12):3867-3877.

23. Bhavikatti SK, BhardwaSj, Prabhuji MLV. Current applications of nanotechnology in dentistry: a review. J Microbiol 2014;72-74.

24. Tomisa AP, Launey ME, Lee JS, Mankani MH, Wegst UG, Saiz E. Nanotechnology Approaches to Improve Dental Implants. Int J Oral Maxillofac Implants 2011;26:25-44. 